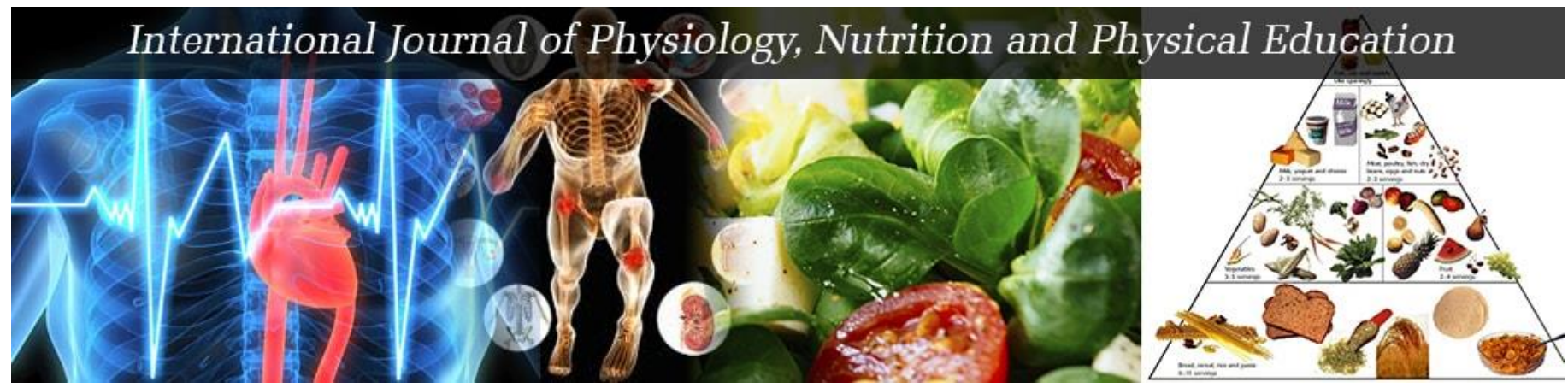

ISSN: 2456-0057

IJPNPE 2021; 6(1): 338-341

(C) 2021 IJPNPE

www.journalofsports.com

Received: 10-01-2021

Accepted: 12-03-2021

Dr. S Saroja

Associate Professor, AUCPE,

Alagappa University, Karaikudi,

Tamil Nadu, India

Dr. R Senthil Kumaran

Director-PE, Directorate of

Physical Education, Alagappa

University, Karaikudi,

Tamil Nadu, India

\section{Effect of Suryanamaskar and physical exercise on selected physiological, bio-chemical and psychological variables among college women}

\author{
Dr. S Saroja and Dr. R Senthil Kumaran
}

DOI: https://doi.org/10.22271/10.22271/journalofsport.2021.v6.i1f.2242

\section{Abstract}

The purpose of the study was to find out the effect of Suryanamaskar and Physical exercise on selected Physiological, Bio-chemical and Psychological variables among College women. To achieve this purpose of the study sixty college women were chosen at random from Alagappa Govt. Arts College, Kariakudi, Sivagangai District. Their age group ranged from eighteen to twenty five, they were divided into four equal groups of fifteen namely. Group I acted as control group who maintained their daily routine activities and no special training was given to them, whereas Group II - Experimental - Suryanamaskar, Group III - Experimental - physical exercise group, Group IV - Experimental - Suryanamaskar and physical exercise underwent their respective treatment for six days per week for twelve weeks. The following variables namely Vital capacity, (Physiological), Blood Sugar (Bio-Chemical) and Anxiety (Psychological) were selected as criterion variables. The selected variables were estimated before and after the training program. The collected data were analyzed statistically through analysis of covariance (ANCOVA) to find out the significant differences, if any among the group. The 0.05 level of confidence was fixed to test the level of significance which was considered as an appropriate. Scheffe's post hoc test was used to find out the paired mean significance difference. The results of the study shows that there was the significant effect on Vital Capacity, Blood sugar and Anxiety due to the influence of Suryanamaskar and physical exercise among college women. It was found that the experimental combined group of Suryanamaskar and physical exercise showed remarkable results followed by the experimental group Suryanamaskar and the experimental group physical exercise.

Keywords: Suryanamaskar, physical exercise, vital capacity, blood sugar, anxiety

\section{Introduction}

Yoga is more than mastering postures and increasing your flexibility and strength. In Hinduism, Buddhism and Jainism the word yoga means "spiritual discipline". People often associate yoga with the postures and stances that make up the physical activity of the exercise, but after closer inspection it becomes clear that there are many more aspects of yoga. It is an activity that has been practiced for thousands of years, and it is something that has evolved and changed overtime. (Swami Satyananda Saraswathi 1991) ${ }^{[3]}$.

The science of Yoga brings to work on the outermost aspect of the personality, the physical body, which for most people is a practical and familiar starting point. When imbalance is experienced at this level, the organs, muscles and nerves no longer function in harmony, rather they act in opposition to each other. Yoga aims at bringing the different bodily functions in to perfect co-ordination so that they work for the good of the whole body. Walking can help in weight control since it burns at least four times more calories than sitting or standing. (William, E. 1980) ${ }^{[4]}$.

Suryanamaskar is an unavoidable part of Yoga. However it is not described in Patangali Yog Sutra, Hathapradipika, Gherandsamita, Yog Vasistha or any main Literature of Yoga. Worshiping Sun as God is there since the Vedic period. However practicing a chain of asana with mantras and pranayama in Suryanamaskar is a recent development- i.e. after 15th - 16th century.

\section{Dr. S Saroja}

Associate Professor, AUCPE, Alagappa University, Karaikudi, Tamil Nadu, India 
Surya Namaskar, an age-old yogic practice, is a comprehensive exercise, which contributes to mental, emotional, physical, and spiritual well-being. Suryanamaskar helps to increase flexibility, endurance and stamina. It tones body muscles and helps to lose weight by activating fat metabolism and normalising hormonal imbalance. It helps to increase mobility in almost all joints. Blood circulation increases all over the body up to organic level, tissue level and cellular level.

Physical exercise is any bodily activity that enhances or maintains physical fitness and overall health and wellness. It is performed for various reasons including strengthening muscles and the cardiovascular system, honing athletic skills, weight loss or maintenance, as well as for the purpose of enjoyment. Frequent and regular physical exercise boosts the immune system, and helps prevent the "diseases of affluence" such as heart disease, cardiovascular disease, cardiovascular disease, diabetes and obesity, It also improves mental health and helps prevent depression Physical exercise "exertion of the muscles, limbs and bodily powers, regarded with, reference to its effect on the subject, especially such exertion undertaking with a view to the maintenance or improvement of health" (Mathews 1981) ${ }^{[6]}$.

\section{Hypothesis}

1. There would be significant differences on the influences of Suryanamaskar and physical exercise among college women.

2. There would be significant differences on the influences of Suryanamaskar among college women.

3. There would be significant differences on the influences of physical exercise among college women.

4. There would be significant differences on the influences of Suryanamaskar among college women better than physical exercise.

\section{Methodology}

For the purpose of this study, sixty college women were chosen as random basis from Alagappa Govt. Arts College Karaikudi, Sivagangai District Their age group ranges from eighteen two twenty five years. They were divided into four groups of fifteen. The experimental group I would undergo control group and the experimental group II would undergo Suryanamaskar, the third group would undergo physical exercise; Suryanamaskar and physical exercise would be for the fourth group. Pre-test and post-tests would be for the variables such as vital capacity, Blood sugar and Anxiety. Treatment would be given for twelve weeks. Analysis of covariance was used for interpreting the results when the ' $F$ ' ratio was significant to find out the significant difference between the parried adjusted means, the post hoc test by Scheffe's method was used. Level of confidence was fixed at 0.5 level (Rothstein 1995) ${ }^{[1]}$.

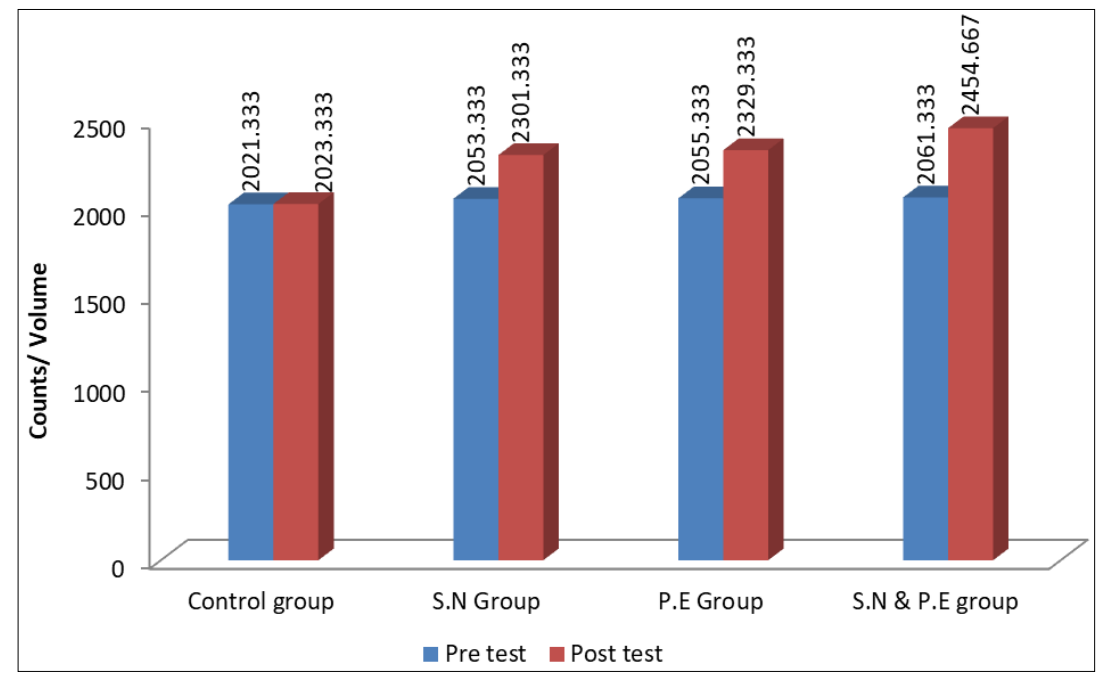

Fig 1: Bar diagram-viral capacity

Table 1: Training scheduled

\begin{tabular}{|c|c|c|c|c|c|c|c|c|c|}
\hline \multirow{2}{*}{ Weeks } & \multirow{2}{*}{ Days } & \multicolumn{2}{|c|}{ Control group } & \multicolumn{2}{c|}{ Suryanamaskar } & \multicolumn{2}{c|}{ Physical exercise } & \multicolumn{2}{c|}{$\begin{array}{c}\text { Suryanamaskar and } \\
\text { physical exercise }\end{array}$} \\
\cline { 3 - 9 } & & Morning & Evening & Morning & Evening & Morning & Evening & Morning & Evening \\
\hline $1,2,3 \& 4$ & Six Days & No Training & No Training & $25 \mathrm{~min}$ & $25 \mathrm{~min}$ & $25 \mathrm{~min}$ & $25 \mathrm{~min}$ & $25 \mathrm{~min}$ & $25 \mathrm{~min}$ \\
\hline $5,6,7 \& 8$ & Six Days & No Training & No Training & $35 \mathrm{~min}$ & $35 \mathrm{~min}$ & $35 \mathrm{~min}$ & $35 \mathrm{~min}$ & $35 \mathrm{~min}$ & $35 \mathrm{~min}$ \\
\hline $9,10,11 \& 12$ & Six Days & No Training & No Training & $45 \mathrm{~min}$ & $45 \mathrm{~min}$ & $45 \mathrm{~min}$ & $45 \mathrm{~min}$ & $45 \mathrm{~min}$ & $45 \mathrm{~min}$ \\
\hline
\end{tabular}

\section{Results and Discussion}

Table 2: Analysis of covariance on vital capacity of control group and experimental groups

\begin{tabular}{|c|c|c|c|c|c|c|c|c|}
\hline \multicolumn{4}{|c|}{ Adjusted post-test mean } & Source & SS & Df & MS & F \\
\cline { 1 - 7 } Control group & S.N. group & P.E. group & $\begin{array}{c}\text { S.N. \& P.E. } \\
\text { group }\end{array}$ & Between & 1230692.257 & 3 & 410230.752 & 41.626 \\
\hline 2047.384 & 2296.342 & 2322.526 & 2442.414 & Within & 542032.978 & 55 & 9855.145 & \\
\hline & & & & &
\end{tabular}

\footnotetext{
* Significant at .05 level of confidence, $\mathrm{df}$ for $3 \& 55$ is 2.78
} 
Table 3: Scheffe's test for difference of the adjusted post-test paired means on vital capacity

\begin{tabular}{|c|c|c|c|c|c|}
\hline \multicolumn{4}{|c|}{ Adjusted post-test mean } & \multirow{2}{*}{ Mean differences } & \multirow{2}{*}{ Confidence interval } \\
\hline Control group & S.N. group & P.E. group & S.N. \& P.E. group & \\
\hline 2047.384 & 2296.342 & & & $248.957^{*}$ \\
\hline 2047.384 & & 2322.526 & & $275.142^{*}$ \\
\hline 2047.384 & & & 2442.414 & 395.030 \\
\hline & 2296.342 & 2322.526 & & 26.185 \\
\hline & 2296.342 & & 2442.414 & $146.073^{*}$ \\
\hline & & 2322.526 & 2442.414 & $119.888^{*}$ & \\
\hline
\end{tabular}

Significant at 0.05 level

The findings of the study showed that the experimental group IV had improved Vital Capacity more than the experimental group III \& II. It was further showed that the experimental group II was better than experimental group I.
The result of the study supported by the findings of V. Hubert Dhanraj which states that there is a significant improvement in Vital Capacity due to regular training.

Table 4: Analysis of covariance on blood sugar of control group and experimental groups

\begin{tabular}{|c|c|c|c|c|c|c|c|c|}
\hline \multicolumn{4}{|c|}{ Adjusted post-test mean } & Source & SS & Df & MS & F \\
\cline { 1 - 6 } Control group & S.N. group & P.E. group & $\begin{array}{c}\text { S.N. \& P.E. } \\
\text { group }\end{array}$ & Between & 9719.389 & 3 & 3239.796 & $21.56^{*}$ \\
\hline 168.573 & 163.094 & 146.141 & 136.926 & & Within & 8266.346 & 55 & 150.294 \\
\hline
\end{tabular}

*Significant at .05 level of confidence, df for $3 \& 55$ is 2.78 .

Table 5: Scheffe's test for difference of the adjusted post-test paired means on blood sugar

\begin{tabular}{|c|c|c|c|c|c|}
\hline \multicolumn{4}{|c|}{ Adjusted post-test mean } & \multirow{2}{*}{ Mean differences } & \multirow{2}{*}{ Confidence interval } \\
\cline { 1 - 4 } Control group & S.N. group & P.E. group & S.N. \& P.E. group & & 5.479 \\
\hline 168.573 & 163.094 & & & $22.432^{*}$ \\
\hline 168.573 & & 146.141 & 136.926 & $31.647^{*}$ \\
\hline 168.573 & & & & $16.953^{*}$ \\
\hline & 163.094 & 146.141 & 136.926 & $26.168^{*}$ \\
\hline & 163.094 & & 136.926 & 9.216 \\
\end{tabular}

*Significant at 0.05 level.

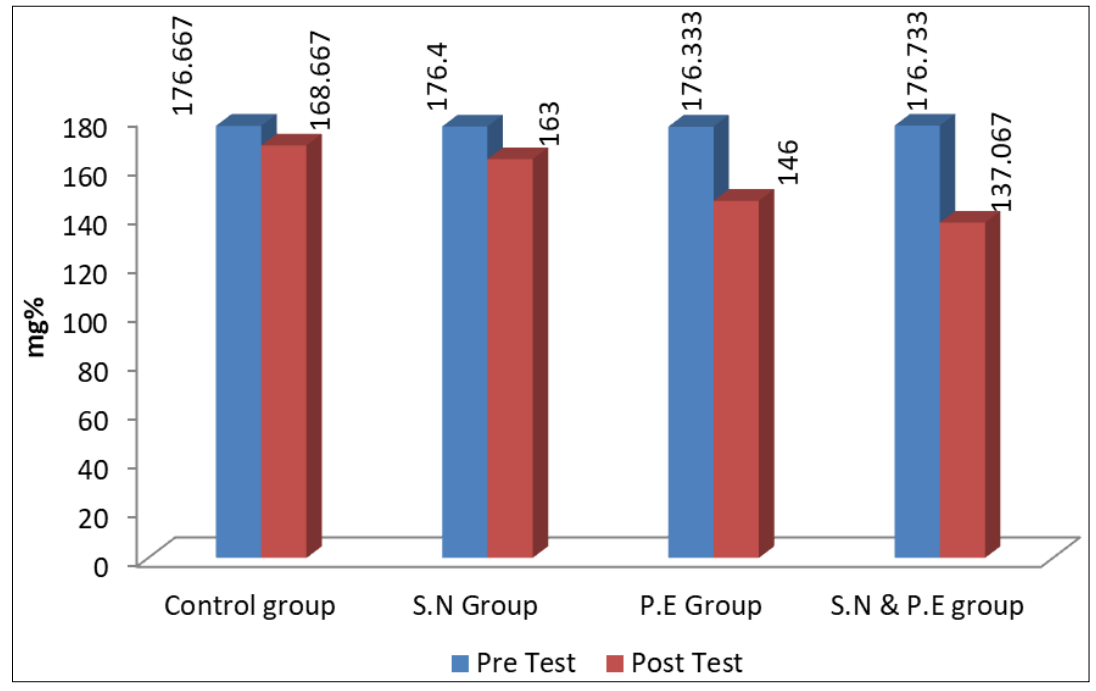

Fig 2: Bar diagram - Blood Sugar

The findings of the study showed that the experimental group IV had reduced Blood Sugar more than the experimental group III \& II. It was further showed that the experimental group II was better than experimental group I in reduction of the Blood Sugar.

Table 6: Analysis of covariance on anxiety of control group and experimental groups

\begin{tabular}{|c|c|c|c|c|c|c|c|c|}
\hline \multicolumn{4}{|c|}{ Adjusted post-test mean } & Source & SS & Df & MS & F \\
\cline { 1 - 6 } Control group & S.N. group & P.E. group & $\begin{array}{c}\text { S.N. \& P.E. } \\
\text { group }\end{array}$ & Setween & 145.740 & 3 & 48.580 & 32.037 \\
\hline 17.988 & 19.529 & 20.796 & 22.220 & & Within & 83.400 & 55 & 1.516 \\
\hline
\end{tabular}

*Significant at .05 level of confidence, df for $3 \& 55$ is 2.78 . 
Table 7: Scheffe's test for difference of the adjusted post-test paired means on anxiety

\begin{tabular}{|c|c|c|c|c|c|}
\hline \multicolumn{4}{|c|}{ Adjusted post-test mean } & \multirow{2}{*}{ Mean differences } & \multirow{2}{*}{ Confidence interval } \\
\hline Control group & S.N. group & P.E. group & S.N. \& P.E. group & & 1.541 \\
\hline 17.988 & 19.529 & & & $2.808^{*}$ \\
\hline 17.988 & & 20.796 & & $4.231^{*}$ \\
\hline 17.988 & & & 22.220 & 1.267 \\
\hline & 19.529 & 20.796 & & $2.690^{*}$ \\
\hline & 19.529 & & 22.220 & $1.423^{*}$ & \\
\hline
\end{tabular}

* Significant at 0.05 level.

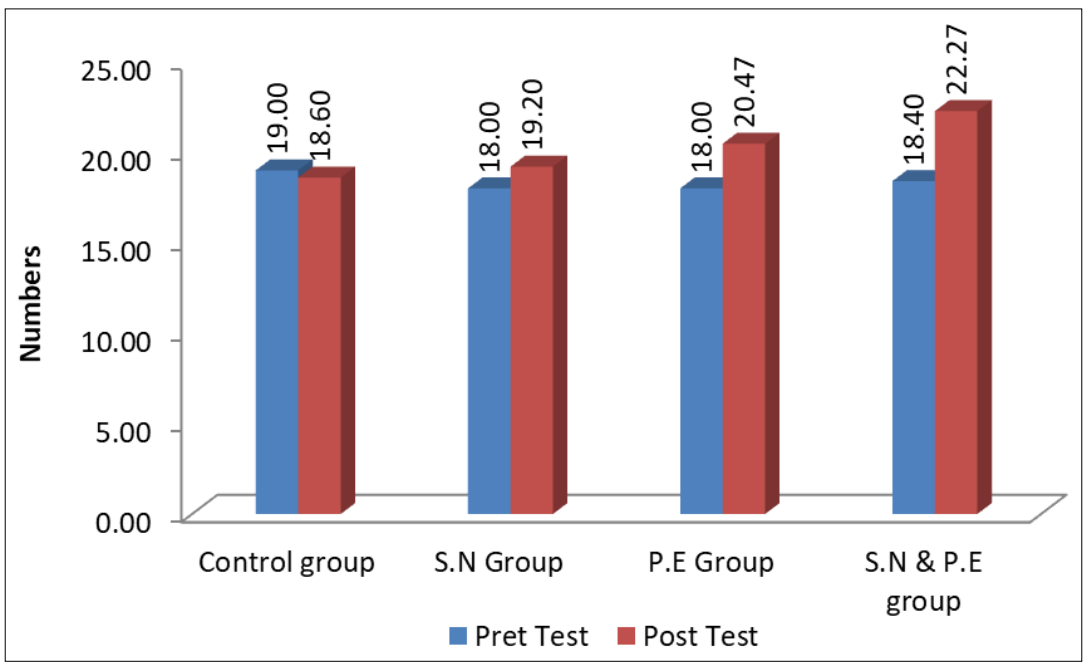

Fig 3: Bar diagram - Anxiety

The findings of the study showed that the experimental group IV had improved Anxiety more than the experimental group III \& II. It was further showed that the experimental group II was better than experimental group I in reduction of the Pulse Rate.

The result of the study supported by the findings of B.K.S. Iyengar and Hasrani (1991) ${ }^{[2]}$ and Robert (1975) ${ }^{[7]}$ which states that there is a significant improvement in Anxiety due to regular training.

\section{Discussion}

1. The findings of the study revealed that there were significant effect due to the influence of Suryanamaskar and physical exercise on, Vital Capacity, Blood Sugar, and Anxiety.

2. The findings of the study showed that there were significant effect due to the influence of Suryanamaskar on Vital Capacity, Blood Sugar and Anxiety.

3. The findings of the study showed that there were significant effect due to the influence of physical exercise on Vital Capacity, Blood Sugar and Anxiety.

4. The findings of the study showed that there was significant improvement due to the influence of Suryanamaskar on Vital Capacity, Blood Sugar and Anxiety than the influence of physical exercise.

\section{Conclusions}

- Vital capacity, Blood sugar and Anxiety, were significantly improved due to the effect of Suryanamaskar and physical exercise.

- The findings of the study showed that the combination of Suryanamaskar and physical exercise is better than Suryanamaskar and physical exercise.

- It was found that the experimental combined group of Suryanamaskar and physical exercise showed remarkable results followed by the experimental group, Suryanamaskar, and physical exercise.

\section{References}

1. Anne Rothstein L. Research design and Statistics for Physical Education 1995.

2. Hasrani SS. "A Comparative Assessment of Pre Competition Anxiety Between Basketball and Track and Field Athletes". A paper presented in the VII National conference on Sports Psychology. Trivandrum 1991, 13.

3. Swami Satyananda Saraswati. Asana Pranayama Mudra Bandha, India: Bihar Yoga Bharati 1997, 1.

4. William D et al. Exercise Physiology, Philadelphia: lea and Febiger 1986, 5.

5. Lyengar KS. Light and Yoga, Australia: George Allen and Unwin Australia Private Ltd 1986, 5.

6. Donald Mathews K. Measurement in physical Education (Philadelphia: W.B. Saunders Company) 1973, 10.

7. Robert Singer N. Myths and Truth Sports Psychology, New York: Harper and Row Publishers 1975, 13. 